\title{
Eligibility for randomized trials of treatments specifically for intracerebral hemorrhage: community-based study
}

\author{
Arthur Fonville $2^{2^{*}}$, Neshika Samarasekera ${ }^{1}$, Yvo Roos $^{2}$, Rustam Al-Shahi Salman ${ }^{1}$ \\ From 2nd Clinical Trials Methodology Conference: Methodology Matters \\ Edinburgh, UK. 18-19 November 2013
}

\section{Background}

There are no acute treatments specifically for intracerebral hemorrhage ( $\mathrm{ICH})$, but they are being sought in randomized controlled trials. The treatment effect sizes in ongoing and future trials are likely to be small, necessitating large sample sizes.

\section{Methods}

We searched online trial registries for randomized controlled trials investigating an acute treatment for $\mathrm{ICH}$. For the trials whose eligibility criteria could be assessed in a prospective, community-based ICH cohort study (2010-11), we quantified the proportions of patients who were eligible and investigated influences on these proportions.

\section{Results}

We applied the eligibility criteria of 17 trials to 166 adults with ICH, of whom between $0.6 \%$ (95\% confidence interval [CI] $0.1-3.3$ ) to $40 \%$ (95\% CI 33-48) were eligible for each trial. Fewer patients were eligible for trials restricted to patients randomized within 12 hours of $\mathrm{ICH}$ onset compared to trials with a longer time window $(\mathrm{p}=0.03)$. Each additional eligibility criterion reduced the portion of eligible patients by $1.3 \%$ (95\% CI 0.4-2.2; adjusted R2 = $0.47 ; \mathrm{p}=0.004)$. At least $66 \%$ (95\% CI 58-73) of the entire cohort was ineligible for all of the six trials that were ongoing at the time of this study.

\section{Conclusion}

Fewer than half of patients with ICH are eligible for current randomized controlled trials. Future trials could maximize enrollment by extending the time window after

${ }^{2}$ Academic Medical Center, University of Amsterdam, Amsterdam, The Netherlands

Full list of author information is available at the end of the article
$\mathrm{ICH}$ onset for recruitment and minimizing the number of eligibility criteria. We are developing an online trial eligibility simulator based on our dataset to assist investigators planning future trials of treatments for $\mathrm{ICH}$.

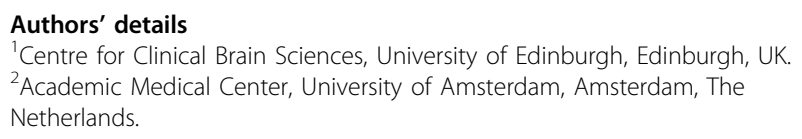

Published: 29 November 2013

doi:10.1186/1745-6215-14-S1-P47

Cite this article as: Fonville et al:: Eligibility for randomized trials of treatments specifically for intracerebral hemorrhage: community-based study. Trials 2013 14(Suppl 1):P47.

Submit your next manuscript to BioMed Central and take full advantage of:

- Convenient online submission

- Thorough peer review

- No space constraints or color figure charges

- Immediate publication on acceptance

- Inclusion in PubMed, CAS, Scopus and Google Scholar

- Research which is freely available for redistribution
C Biomed Central

@ 2013 Fonville et al; licensee BioMed Central Ltd. This is an Open Access article distributed under the terms of the Creative Commons Attribution License (http://creativecommons.org/licenses/by/2.0), which permits unrestricted use, distribution, and reproduction in any medium, provided the original work is properly cited. 